\title{
Recall of rapidly presented random chess positions is a function of skill
}

\author{
FERNAND GOBET and HERBERT A. SIMON \\ Carmegie Mellon University, Pittsburgh, Pennsylvania
}

\begin{abstract}
A widely cited result asserts that experts' superiority over novices in recalling meaningful material from their domain of expertise vanishes when they are confronted with random material. A review of recent chess experiments in which random positions served as control material (presentation time between 3 and $10 \mathrm{sec}$ ) shows, however, that strong players generally maintain some superiority over weak players even with random positions, although the relative difference between skill levels is much smaller than with game positions. The implications of this finding for expertise in chess are discussed and the question of the recall of random material in other domains is raised.
\end{abstract}

A classical result in the study of expertise is that experts are better than nonexperts at memorizing meaningful material from their domain of expertise, but lose their superiority when the material is randomized. This result was first obtained in the study of chess memory (Chase \& Simon, 1973b; Jongman \& Lemmens, cited in Vicente \& De Groot, 1990) and has since been widely cited in cognitive psychology textbooks (see, e.g., Anderson, 1990; Lesgold, 1988) and hailed as one of the cornerstones of the study of expertise (Saariluoma, 1989). The basic relation between skill and meaningfulness has been replicated in various domains, although wide variations in the presentation time of the stimuli make quantitative comparisons difficult: Go (Reitman, 1976); bridge (Charness, 1979; Engle \& Bukstel, 1978); Othello (Wolff, Mitchell, \& Frey, 1984); electronics (Egan \& Schwartz, 1979); computer programs (McKeithen, Reitman, Rueter, \& Hirtle, 1981); basketball (Allard, Graham, \& Paarsalu, 1980). Some studies, however, have found that experts keep their superiority over novices when the material is memory for randomized sequences of pitch symbols (Sloboda, 1976) and dance sequences (Allard \& Starkes, 1991).

A complete lack of difference in memory for random material between experts and nonexperts is somewhat counterintuitive. Simon and Chase (1973) have proposed that $10,000 \mathrm{~h}$, or about 10 years, of intense practice and study are necessary to reach a high level of expertise. During their practice and study time experts have undoubtedly met with many situations that are close to "random"; that is, situations containing some infrequently

Preparation of this article was supported by Grant No. 8210-30606 from the Swiss National Funds of Scientific Research to F.G. and Grant No. DBS-912-1027 from the National Science Foundation to H.A.S. The authors extend their thanks to Neil Charness, David Lane, Howard Richman, Pertti Saariluoma, Jim Staszewski, and Shmuel Ur for valuable comments on parts of this research. Correspondence should be addressed to H. A. Simon, Department of Psychology, Carnegie Mellon University, Pittsburgh, PA 15213 (e-mail: has@cs. cmu.edu). observed features. In the frame of Chase and Simon's (1973a) chunking theory, one would expect that the numerous chunks experts have stored in long-term memory (LTM) including some of these unusual features, would allow them to recognize, more often than weak players, familiar chunks that occur adventitiously in random positions, giving them an advantage in recall. It is also possible that strong players have developed strategies to cope with uncommon situations, which do occur sometimes in their practice. In addition, their familiarity with the materials (e.g., in board games, better knowledge of the topology of the board and its attributes) might give them some advantage over nonexperts.

In this paper, we reexamine the recall of random material as a function of level of expertise, emphasizing the chess domain mainly because many empirical data are available there, and because the ELO ${ }^{1}$ scale allows players to be ranked much more precisely than just as "experts" and "novices," as is the case in other research domains on expertise. We shall see that there has been some oversimplification of the empirical findings on recall of random chess positions in that small but statistically significant effects have been ignored.

Random positions have been used mainly as a control of subjects' general (non-domain-specific) memory capacity, but some researchers have studied them for their own sake. For example, Holding and Reynolds (1982) used semi-random positions to study problem solving in chess, and Reynolds (1982) has shown that different degrees of randomness can be obtained by manipulating the amount of control that the pieces have over the center.

Some researchers have found skill differences in recall performance when the presentation time is sufficiently long. Djakow, Petrowski, and Rudik (1927) presented a random position for $1 \mathrm{~min}$ to Masters and to subjects in a non-chess-playing control group, and found that the Masters' recall was better than that of the control subjects. However, two difficulties cloud the interpretation of this study. First, the control group subjects did not play chess at all, and hence were probably wholly unfamiliar 
with the material. Second, the position was a chess problem. Chess problems are specially constructed situations where the first goal is to construct esthetic positions and combinations. Although this species of chess is quite different from normal chess games, it employs positions that are far from random. Lories (1987) found an effect of skill with 1-min presentations of the semi-random positions ${ }^{2}$ generated by Holding and Reynolds (1982).

In addition, Saariluoma (1989) used a procedure similar to that of Chase and Ericsson (1982) for the memory of digits, dictating positions at the pace of 2 or $4 \mathrm{sec}$ per piece. He found that strong players were better in the recall of both game and random positions. Finally, Goldin (1979) and Saariluoma (1984) showed that skilled players performed better than less skilled players in a recognition task, both with game and random positions and both with long presentation times (no limit in the study time in Goldin, 1979) and short presentation times (8 sec in Saariluoma, 1984).

Although it is agreed that Masters do better with random positions in some special memory tasks, like those studied by Saariluoma (1989), the general view among students of expert memory has been that there is no difference in recall with the standard presentation time of $5 \mathrm{sec}$ (see, e.g., Cooke, Atlas, Lane, \& Berger, 1993; Ericsson \& Charness, 1994; Holding, 1985). However, an analysis of data from various experiments in the literature that used recall of random positions as a control condition makes it clear that strong players show rather reliably a superiority over weaker players. Table 1 lists all the experiments we have found bearing on this question, with the additional criteria that the presentation time should be at most $10 \mathrm{sec}$, that the mean number of pieces per position should be at least $20,{ }^{3}$ and that the positions used should be generated by a truly random procedure (see note 2 ).
In all cases, except in Chase and Simon's (1973b) study, recall performance increases monotonically as a function of skill. The $F, t$, or $p$ values are not systematically reported in these studies, so we cannot use such meta-analytical approaches as combining tests or computing the overall effect size. We observe, however, that the strongest skill group outperformed the weakest in 12 cases out of 13. Assuming a binomial distribution and equal probability of the strongest group performing better or worse than the weakest, the probability of the strongest group outperforming the weakest in 12 or more cases is .0017 . Alternatively, we can analyze the data in Table 1 using a randomized block design, with skill level as independent variable and experiment as blocking variable. Again, skill levels differ reliably $[F(3,17)=10.35$, $\left.M S_{\mathrm{e}}=0.97, p<.001\right]$. Note finally that the type of reconstruction-board and pieces, dictation, or computer display-did not influence performance $[F(2,27)=$ $0.90, M S_{\mathrm{e}}=2.54$, n.s.].

We see that for each experiment, with the exception of Chase and Simon's results (1973b), where the Master performed worse than the novice, the more skilled players did remember more pieces on random boards than did the less skilled. That these differences were in most cases not statistically significant may be explained both by the small size of the effect and by the small number of subjects in these experiments. In a study aimed at extending the present findings (Gobet \& Simon, 1995), the presentation time was systematically varied from 1 to $60 \mathrm{sec}$. It was found that skill differences were present at all presentation times, although they were larger with long presentation times.

We must deal at the outset with a plausible explanation for this skill difference, suggested to us by Neil Charness: that chess Masters guess better and more often than do novices. Jongman's (1968) finding that strong players

Table 1

Number of Pieces Correctly Replaced for Random Positions as a Function of Skill in 13 Experiments

\begin{tabular}{|c|c|c|c|c|c|c|c|}
\hline \multirow[b]{2}{*}{ Source } & \multirow[b]{2}{*}{$N$} & \multirow{2}{*}{$\begin{array}{c}\text { Presentation } \\
\text { Time }\end{array}$} & \multirow[b]{2}{*}{ Reconstruction } & \multicolumn{4}{|c|}{ Mean Rating (in ELO Points) ${ }^{*}$} \\
\hline & & & & $<1600$ & $1600-1999$ & $2000-2350$ & $>2350$ \\
\hline a,g Chase \& Simon (1973b) & 3 & 5 & Board & 3.0 & 2.5 & & 2.0 \\
\hline a,g Frey \& Adesman (1976) & 13 & 8 & Board & 2.0 & 2.5 & & \\
\hline c,h Saariluoma (1984, Exp. 3) & 4 & 5 & Board & 2.4 & 3.8 & & \\
\hline${ }^{c}$ Saariluoma (1984, Exp. 4) & 4 & 5 & Board & 2.5 & & 5.0 & 7.3 \\
\hline c,g Saariluoma (1985, Exp. 3) & 9 & 5 & $?$ & 2.6 & 3.8 & 4.6 & \\
\hline $\mathrm{b}, \mathrm{d}, \mathrm{g}$ Gold \& Opwis (1992) & 40 & 10 & Board & 3.0 & 4.3 & & \\
\hline c,e,g Saariluoma (1994, Exp. 1) & 12 & 5 & Board & 3.0 & & 5.8 & \\
\hline c,d,g Saariluoma (1994, Exp. 2) & 9 & 3 & Verbal & 2.4 & 3.4 & 4.8 & \\
\hline c,g Saariluoma (1994, Exp. 3) & 8 & 5 & Verbal & 2.4 & & 6.0 & \\
\hline c,f,g Saariluoma (1994, Exp. 4) & 10 & 3 & Verbal & 2.4 & 2.9 & & \\
\hline b,f Gobet \& Simon (1995, Exp. 1) & 21 & 5 & Computer & & 3.4 & 5.2 & 8.4 \\
\hline${ }^{\mathrm{b}}$ Gobet \& Simon (in press-a, Exp. 2) & 13 & 5 & Computer & & 3.0 & 4.0 & 5.2 \\
\hline${ }^{\mathrm{b}}$ Gobet \& Simon (in press-b, Exp. 1) & 25 & 5 & Computer & & 3.1 & 3.4 & 3.6 \\
\hline
\end{tabular}

Note-For each experiment, the table lists, in order: the source, the number of subjects, the presentation time in seconds, the reconstruction mode, and the number of pieces correctly replaced. " The group mean rating is used for classification. a U.S. Chess Federation rating is used. ${ }^{b}$ International rating, or equivalent, is used. ${ }^{c}$ Finnish rating is used. $\mathrm{d}$ The difference between skill levels is significant at the .05 level. ' This corrects an error in Saariluoma's (1994) Figure 2, where the labels for the TT and random positions have been swapped (Saariluoma,

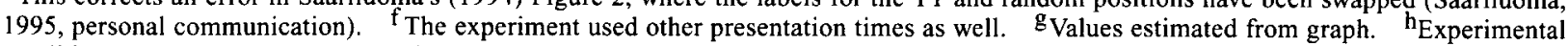
conditions with 20 and 25 pieces pooled. 
were not better than weaker players in guessing the zeroorder probability of piece location in game positions suggests that it is not likely that strong players guess better with random material. Whether strong players guess more often can be checked against the number of errors of commission they make. As data on errors of commission are not available for all the studies listed in Table 1, we will restrict our analysis to experiments run by our own research group. In Gobet and Simon (in press-a), Masters, Experts, and Class A players committed, on average, $2.4,5.5$, and 3.9 errors of commission with random positions presented for $5 \mathrm{sec}$ each. The differences were not significant statistically. In Gobet and Simon (1995), where the presentation time was varied from 1 to $60 \mathrm{sec}$, players of all skill levels tended to make more errors of commission with longer presentation times, and Masters tended to make fewer errors of commission than did Experts and Class A players. Again, the differences were not statistically significant. With $5 \mathrm{sec}$, the respective errors of commission were 1.0,3.1, and 3.4, for Masters, Experts, and Class A players, respectively. On the basis of these data and Jongman's results, we can safely reject the hypothesis that the differences we found were due to stronger players' guessing more often or better than weaker players.

Thus, although randomization does severely reduce the recall of strong players, it does not completely destroy their superiority over weaker players. Note that this skill difference in recall with random positions is small (roughly one piece per additional 400 ELO points), much less than for the recall of game positions, where an increase of 400 ELO points typically yields an increase of about five pieces. Figure 1 , which summarizes the data of Table 1 and gives the mean number of pieces correct for the game positions obtained in the same experiments, makes it clear that the slopes are different in the two cases.

Does this finding challenge the prevailing theory that experts' superiority of recall (especially with game po-

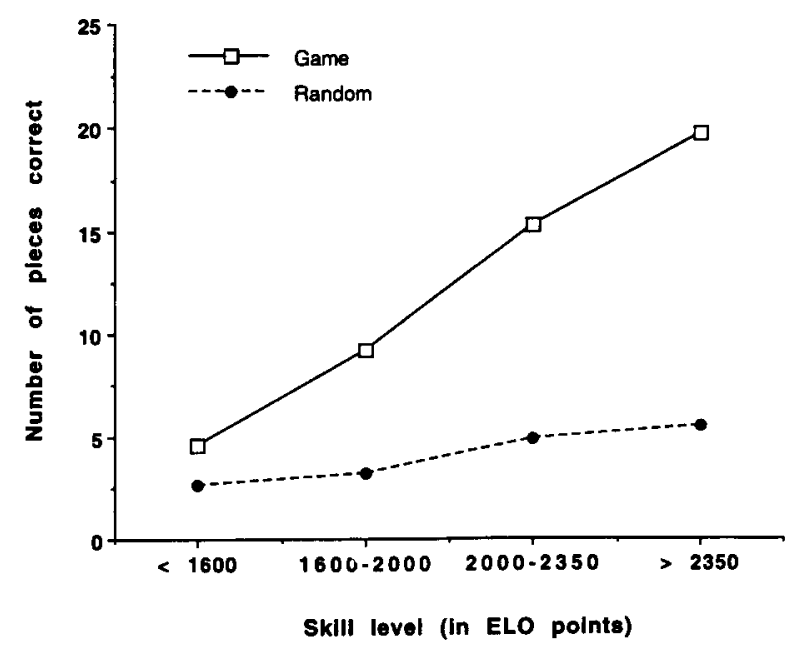

Figure 1. Mean number of pieces placed correctly as a function of type of positions (game or random) and skill level. sitions) rests on their superior store of chess knowledge? We conclude that it does not. First, the few studies that have investigated the general cognitive abilities of chess players outside the domain of chess (for reviews, see Cranberg \& Albert, 1988; De Groot, 1946, 1978; or Gobet, 1993) have found no superiority for chess players over non-chess players, nor is there a correlation between level of skill and general cognitive abilities. For example, Djakow et al. (1927) subjected top-level Masters to a battery of psychological tests, including a visual memory test using $8 \times 8$ matrices having or not having a resemblance to chessboards. Masters performed better than did control subjects when tests involved chess material, but not in tests unrelated to chess. (A later exception is the Subject V.P. studied by Hunt and Love, 1972, who was both a mnemonist and a strong chess player.)

Second, the skill difference with random positions is predicted by Chase and Simon's (1973a) chunking theory in that Masters, having a larger repertoire of chunks in LTM, are more likely to find rare patterns in LTM than are weaker players. ${ }^{4}$ This is confirmed by computer simulations (Gobet \& Simon, in press-a) in which the program's recall of random positions increased logarithmically as a function of the number of chunks that had been learned through the study of game positions.

What processes allow strong players to perform better than weak players with random positions? We have suggested three possibilities: (1) a large database of chunks in LTM, occasionally allowing the recognition of stored patterns that occur by chance in random positions; (2) the possession of strategies for coping with uncommon positions; and (3) better knowledge of the topology of the chessboard. We have just seen that the first hypothesis is supported by computer simulation. We are aware of no specific evidence for the second hypothesis. The third hypothesis - better knowledge of the topology of the board-is supported by Saariluoma's (1991) data, which show that Masters are better than novices at deciding whether a square, denoted by its algebraic notation (e.g., "e4") is white or black. Following this hypothesis, Masters possess chunks of squares (with or without pieces on them), that may be used in random positions to organize patterns of pieces. For example, Masters may know that the squares "a1" and " 2 " are at a knight's distance, and may use this schema of squares to encode the pattern "white pawn al, black pawn c2," even though, because the rules of the game prohibit pawns on the first rank, they are not likely to have learned this precise chunk through past experience.

In this paper, we have reviewed several chess recall studies that used random positions as a control task, with a presentation time ranging from 3 to $10 \mathrm{sec}$. We found that, contrary to the general opinion, the recall of random position varies somewhat as a function of chess skill, and we proposed an explanation of this effect that is supported by our computer simulations. Although the absolute difference between skill levels is small, its presence rules out some theoretical accounts of chess expertise that have been proposed as alternatives to the chunk- 
ing theory. Without an ad hoc assumption-perhaps familiarity with chess material-it is hard to see how theories of chess skill based mainly on level of processing (Lane \& Robertson, 1979) or high-level knowledge (Cooke et al., 1993) can account for this observed, if modest, effect with random positions. By accessing chunks (not information at a "deeper level") already stored in LTM, our computer model of the expert occasionally detects and recalls adventitious patterns on the random boards. The level-of-processing theory would require accessing "higher knowledge" in LTM, but it is not obvious what "higher knowledge" could be used in recalling random positions, which, by construction, have no deeper structure.

As with chess, most studies on experts' memory in other tasks have used small numbers of subjects (Charness, 1988; Gobet, 1993). It is a question for future research whether the lack of difference between experts and nonexperts found in various domains of expertise when random material was used is genuine or is due to the low power of the experimental design used in these studies.

Taken together with results on the memory for sequence of pitch symbols (Sloboda, 1976) and for dance sequences (Allard \& Starkes, 1991), the studies reviewed in this paper indicate that the relation between expertise and "meaningless" material taken from the domain of expertise may be somewhat more complex than has been thought previously, but that the notion of chunking is able to account for most of the phenomena, quantitatively as well as qualitatively.

\section{REFERENCES}

Allard, F., Graham, S., \& Paarsalu, M. E. (1980). Perception in sport: Basketball. Journal of Sport Psychology, 2, 22-30.

Allard, F., \& Starkes, J. L. (1991). Motor-skill experts in sports, dance and other domains. In K. A. Ericsson \& J. Smith (Eds.), Toward a general theory of expertise: Prospects and limits (pp. 126152). Cambridge: Cambridge University Press.

ANDERSON, J. R. (1990). Cognitive psychology and its implications. New York: Freeman.

Charness, N. (1979). Components of skill in bridge. Canadian Journal of Psychology, 33, 1-16.

Charness, N. (1988). Expertise in chess, music and physics: A cognitive perspective. In L. K. Obler \& D. Fein (Eds.), The exceptional brain: Neuropsychology of talent and special abilities. New York: Guilford.

Chase, W. G., \& Ericsson, K. A. (1982). Skill and working memory In G. H. Bower (Ed.), The psychology of learning and motivation (Vol. 16, pp. 1-58). New York: Academic Press.

Chase, W. G., \& Simon, H. A. (1973a). The mind's eye in chess. In W. G. Chase (Ed.), Visual information processing (pp. 215-281). New York: Academic Press.

Chase, W. G., \& Simon, H. A. (1973b). Perception in chess. Cognitive Psvchology, 4, 55-81.

Cooke, N. J., Atlas, R. S., Lane, D. M., \& Berger, R. C. (1993). Role of high-level knowledge in memory for chess positions. American Journal of Psychology, 106, 321-351.

Cranberg, L. D., \& Albert, M. L. (1988). The chess mind. In L. K. Obler \& D. Fein (Eds.), The exceptional brain: Neuropsychology of talent and special abilities (pp. 156-190). New York: Guilford.

DE Groot, A. D. (1946). Het denken van den schaker. Amsterdam: Noord Hollandsche.
De Groot, A. D. (1978). Thought and choice in chess (2nd ed.). The Hague: Mouton

Djakow, I. N., Petrowski, N. W., \& Rudik, P. A. (1927). Psychologie des Schachspiels. Berlin: Mouton de Gruyter.

Egan, D. E., \& SchWARTZ, E. J. (1979). Chunking in recall of symbolic drawings. Memory \& Cognition, 7, 149-158

ENGLE, R. W., \& BUKSTEL, L. (1978). Memory processes among bridge players of differing expertise. American Journal of Psychology, 91, 673-689.

Ericsson, K. A., \& Charness, N. (1994). Expert performance: Its structure and acquisition. American Psychologist, 49, 725-747.

Frey, P. W., \& ADESMAN, P. (1976). Recall memory for visually presented chess positions. Memory \& Cognition, 4, 541-547.

Gobet, F. (1993). Les mémoires d'un joueur d'échecs. Fribourg, Switzerland: Editions Universitaires

Gobet, F., \& Simon, H. A. (1995). Role of presentation time in recall of game and random chess positions (Complex Information Paper No. 524). Pittsburgh: Carnegie Mellon University.

GoBET, F., \& Simon, H. A. (in press-a). Recall of random and distorted chess positions: Implications for the theory of expertise. Memory $\&$ Cognition.

Gobet, F., \& Simon, H. A. (in press-b). Templates in chess memory: A mechanism for recalling several boards. Cognitive Psychology.

Gold, A., \& Opwis, K. (1992). Methoden zur empirischen Analyse von Chunks beim Reproduzieren von Schachstellungen. Sprache \& Cognition, 11, 1-13.

GoLdIN, S. E. (1979). Recognition memory for chess positions: Some preliminary research. American Journal of Psychology, 92, 19-31.

Holding, D. H. (1985). The psychology of chess skill. Hillsdale, NJ: Erlbaum.

HoldiNG, D. H., \& REYNOLDS, R. I. (1982). Recall or evaluation of chess positions as determinants of chess skill. Memory \& Cognition, 10, 237-242.

Hunt, E., \& Love, T. (1972). How good can memory be? In A. W Melton \& E. Martin (Eds.), Coding processes in human memory (pp. 237-268). New York: Wiley.

Jongman, R. W. (1968). Het oog van de meester. Assen. The Netherlands: Van Gorcum

LANE, D. M., \& RoBERTSON, L. (1979). The generality of the levels of processing hypothesis: An application to memory for chess positions. Memory \& Cognition, 7, 253-256.

Lesgold, A. (1988). Problem solving. In R. J. Sternberg \& E. E. Smith (Eds.), The psychology of human thought. Cambridge: Cambridge University Press.

LoRIEs, G. (1987). Recall of random and non random chess positions in strong and weak chess players. Psychologica Belgica, 27, 153-159.

McKeithen, K. B., Reitman, J. S., Rueter, H. H., \& Hirtle, S. C. (1981). Knowledge organization and skill differences in computer programmers. Cognitive Psychology, 13, 307-325.

Reitman, J. S. (1976). Skilled perception in Go: Deducing memory structures from inter-response times. Cognitive Psychology, 8, 336356.

REYNOLDS, R. I. (1982). Search heuristics of chess players of different calibers. American Journal of Psychology, 95, 383-392.

SAARILUOMA, P. (1984). Coding problem spaces in chess: A psychological study (Commentationes Scientiarum Socialium 23). Turku, Finland: Societas Scientiarum Fennica.

SAARILUOMa, P. (1985). Chess players' intake of task-relevant cues. Memory \& Cognition, 13, 385-391.

SAARILUOMA, P. (1989). Chess players' recall of auditorily presented chess positions. European Journal of Cognitive Psychology, 1, 309 . 320 .

SaARILuoma, P. (1991). Aspects of skilled imagery in blindfold chess. Acta Psychologica, 77, 65-89.

SAARILUOMA, P. (1994). Location coding in chess. Quarterly Journal of Experimental Psychology, 47A, 607-630.

Simon, H. A., \& Chase, W. G. (1973). Skill in chess. American Scientist, 61, 393-403

Sloboda, J. A. (1976). Visual perception of musical notation: Registering pitch symbols in memory. Quarterly Journal of Experimental Psychology, 28, 1-16. 
VICENTE, K. J., \& De Groot, A. D. (1990). The memory recall paradigm: Straightening out the historical record. American Psychologist, 45, 285-287.

WolfF, A. S., Mitchell, D. H., \& Frey, P. W. (1984). Perceptual skill in the game of Othello. Journal of Psychology, 118, 7-16.

\section{NOTES}

1. Chess players are ranked according to the ELO rating, an interval scale used internationally. Grandmasters are usually rated above 2500 ELO, International Masters above 2400, Masters between 2200 and 2400. Experts between 2000 and 2200, Class A players between 1800 and 2000. Class B players between 1600 and 1800 , and so on The ratings of the U.S. Chess Federation (USCF) are slightly higher than international ELO ratings. Given the large interval classes we will use in this paper, we may ignore the latter difference. The ELO rating system was devised by chessmaster Arpad Elo
2. Lories' (1987) study is difficult to interpret because the positions he used, taken from Holding and Reynolds (1982), are not really random. Some (semantic) constraints were applied in generating the positions, such as no pawn on the first or eighth rank or no piece attacked without being defended. As a matter of fact, a statistical analysis shows that equiprobability of white and black pieces' distribution on the board may be rejected at $p<.001$ (Gobet, 1993).

3 . When the range was given instead of the mean number of pieces per position in the description of the experiment, we took the range midpoint.

4. Though the patterns are produced by chance, they will be recognized if already stored in memory, as in noticing 13 spades in a hand dealt at bridge.

(Manuscript received July 12, 1995; revision accepted for publication November 15,1995 .) 